\title{
IMPLICATION OF TRADITIONAL ECOLOGICAL KNOWL- EDGE ON FOREST RESOURCE MANAGEMENT
}

Dhruba LAUDARI

\section{ABSTRACT}

The primary approaches within contemporary ecological anthropology are cultural ecology, historical ecology, political ecology and spiritual ecology. The cumulative approach developed on by fusing these approaches is applied dimension of ecological anthropology known as environmental anthropology. Human populations have ongoing contact and impact upon the land, climate, plant and animal species in their vicinities and these elements of their environment have reciprocal impacts on humans. The theme of traditional ecological knowledge is important for the consideration of a broad range of question related to nature-environment relations. Different groups of people in various parts of the world perceive and interact with nature differently, and have different traditions of environmental knowledge. Their perceptions and knowledge are partly shaped by their values, worldview and environmental ethics. In the exploration of environmental ethics and religion toward an ecologically sustainable society, indigenous peoples and traditional ecological knowledge have attracted considerable attention from both scholars and popular movements. The lesson from this field study, under the theoretical outline of cultural and human ecology includes the importance of cultural conservation of forest resources, adaptive management, uses of traditional ecological knowledge and development of religious/spiritual conservation ethic. This may contribute to the development of an interdisciplinary conservation science with a more sophisticated understanding of social-ecological interactions. The findings thus could be used for formulating better policies for sustainable management of forest/natural resources.

KEY WORDS: Biodiversity Conservation, Ecological Anthropology, Ethno-ecology, Forest Resource Management, Traditional Ecological/Environmental Knowledge, Religion Ecology.

\section{PROLOGUE}

There are two theoretical approaches that are under use for the study of the interaction between human beings and environment. These two ap- 
proaches are techno-centric approach and eco-centric approach. Based on them, relationship between man and environment is analyzed. Different ecological theories have been proposed and established to investigate the interaction of human beings and their environment. The concept of "evolution of organism" given by Charles Darwin and "ecological system" by Ernest Hackle are important concepts in shaping the development of ecological studies in Anthropology. Frake (1962) introduced a new approach known as 'Ethnoscience' or 'Ethnoecology' in the field of ecological/environmental anthropology. The relationship between traditional ecological knowledge and biological science has always close relation in ethnobiology and in the broader field of ethnosciences like ethnobotany, ethnozoology and ethnopedology etc.

Understanding the trend of indigenous resource management system is essential in the arena of sustainable natural resource management. Forest management system of indigenous societies is rooted in the cultural values, norms and belief systems practiced by such communities. Traditional ecological knowledge operating at the eco-cultural level is a recent development and is a powerful tool for sustainable management of forest/natural resources. Himalayan forests are taken as a part of a cultural landscape linked to livelihood concerns of those who are living in close with nature and natural resources. Indigenous people generally hold excellent knowledge about the reproductive habits and life history of plant and animal species.

There are many areas in which traditional ecological knowledge is significant. First, it is a source of biological knowledge and ecological insights. Second, indigenous knowledge is important for the sustainability of 'difficult-to-manage' ecosystems such as tropical and mountain rain forest. Third, it is important for community-based nature resource management and conservation by connecting human value with conservation ethics. Fourth, this knowledge systems offer special interests for biodiversity conservation, as it is based on multiple use principles. Fifth, in-depth local environmental knowledge and trends developed over time for a given site are important for environmental assessment and monitoring. Sixth, it is essential for "bottom-up" development planning for effective conservation of biodiversity. 
It is worth noting that despite growing awareness of traditional ecological knowledge in the field of natural resources management, such knowledge systems are rapidly vanishing in a number of Asian countries. Traditional knowledge embedded in the cultural practices is likely to be lost irretrievably when the culture or society experiences drastic socio-economic changes. The loss of traditional ecological knowledge, thus, influences local level land-use-practices and forest resource management. One of the causes of failure of mainstream sustainable forest management is due to the lack of attention given for addressing the importance of traditional ecological knowledge systems to policies designed for forest management. It is most essential to incorporate traditional ecological knowledge systems into scientific forest management systems.

Over exploitation of natural resources in favor of capital formation is the prominent factor for depletion of such resources. This has results various problems like land degradation, desertification, denudation, landslides, floods, drought and several other environmental hazards. It is mistaken to view forest management practice only in the term of silvicultural approach. This issue has to be viewed in conjunction with the social, cultural, religious and ecological dimensions for its sustainability. The paradigm shift concept of forest management view forest management as an integrative approach designed with combination of socio-cultural and ecological phenomenon served to sustain human needs and ecosystem complexity.

The term "tradition" used in describing traditional ecological knowledge systems does not imply that this knowledge system is old, fashioned out or non-technical in nature, but is considered as "traditionbased", because it is created in a manner that reflects the traditions of the communities. Over many generations indigenous people have developed a holistic traditional ecological knowledge system of their lands, natural resources and environment, which is a more or less integrated knowledge system that focuses more on cultural adjustment to bio-physical environment at local level. This research in a way helps in identification and documentation of traditional ecological knowledge 
system, which is a fundamental approach for preserving such knowledge systems both for current and future generation, as well as for protecting intellectual property rights of indigenous/traditional communities.

\section{CONSEQUENCE}

Anthropologists are the specialists who bridge the natural and social sciences through application of various ethno-sciences. Ecological anthropologists are well trained to explore, document and manage the connection among sacred places, cultural values, religion, biodiversity, conservation and sustainable development. Development of new paradigm in the field of sustainable resource management considers significant role of anthropologist for forest resource management and overall bio-diversity conservation. The use of traditional ecological knowledge systems in the form of customary ecological management practices has been recognized as a powerful conservation mechanism particularly in indigenous communities. Implication of traditional ecological knowledge systems function well if the forest management objectives are motivated with ecosystem maintenance instead of economy. This study encloses the following significance:

- It helps in the documentation of traditional ecological knowledge systems concerning forest resource management, which could assist for formulating better policy for conservation and management of forest/ natural resources particularly in lower Manang.

- This could contribute to the role of anthropologist, with the notion of anthropological perspective, as nature conservation so far has only been the concern of foresters, environmentalists, ecologists or biologists.

\section{INTENTION}

The broad objective of the research is to explore the role of Traditional Ecological Knowledge (TEK) system and traditional institution for sustainable management of forest resource in lower Manang. The specific objectives are-

1. To explain norms and value systems pertaining to the conservation 
and management of forest resource in lower Manang.

2. To describe local processes and actors involved in the communication and exchange of traditional ecological knowledge system.

3. To explore the implicative role of religion, cultural values and belief systems for management of forest biodiversity in lower Manang.

\section{PARADIGM SHIFT CONCEPT IN FOREST MANAGEMENT}

Traditionally foresters defined a sustainably managed forest as one which results in maximum timber harvest with maximum economic profit. In recent years, this definition has expanded to encompass economic, environmental and social qualities that contribute to the sustainability of forest dependent communities and ecosystems as well as the forest itself. The paradigm shift perspective of eco-centric forest management approaches focus on the principle that human should not see themselves as an external manager of forest resources. Instead, human beings must consider themselves as an integral component of forest ecosystem or bio-diversity.

The 'institutional change' perspective considers that professional organization should esteem indigenous knowledge and try consciously to incorporate features of 'rehabilitated' indigenous management systems into their own formal method. This is done through indulging bottomup development approaches by generating people's participation for enhancing goal of sustainable development. Traditional ecological knowledge system thus contributes in achieving ecological, social, economic and cultural sustainability of indigenous people. Traditional ecological knowledge represents multiple bodies of knowledge accumulated through many generations in close interactions between people and the natural environment.

\section{THEORETICAL OVERVIEW}

\section{TRADITIONAL ECOLOGICAL KNOWLEDGE (TEK)}

Traditional Ecological Knowledge (TEK) is a sub-set of indigenous knowledge system apprehended by indigenous people. It is also recognized as local knowledge unique to a given culture or society. Traditional ecological knowledge is rational and reliable knowledge that 
Implication traditional...... Laudari

has been developed through generation of intimate contact by native people with their lands. Traditional ecological knowledge as a modern concept has its birth in the marriage of ethno-biology and human ecology. As defined by Berkes (2008), 'TEK' encompasses (i) factual knowledge about ecological components and processes (ii) knowledge put into practices about environmental use, and (iii) the cultural values and philosophies that define human relationship with their surrounding environment and in wider prospect to natural world.

Despite, its widespread use, the term 'traditional ecological knowledge', is a problematic and fairly ambiguous term. In Sacred Ecology (1999:8), Berkes arrives at a working definition of traditional ecological knowledge system as "A cumulative body of knowledge and beliefs handed down through generation by cultural transmission, about the relationship of living beings (including humans) with one another and with their environment." On using the word "traditional" in the context of traditional ecological knowledge system, it is important to clarify that such knowledge system is cumulative and open to change. The meaning of 'traditional' therefore simply refers to a time-tested and wise knowledge system, adopted by the local communities in specific time period.

As defined by Warren (1996), Traditional ecological knowledge refers to the knowledge, innovations and practices of indigenous communities around the world. It tends to be collectively owned and takes the form of stories, songs, proverbs, beliefs, rituals, community laws, local language and agricultural practices, including the development of plant species and animal breeds. Traditional ecological knowledge is typically transmitted through oral statement and shared experience rather than through written communication and demonstration. Traditional ecological knowledge is based on empirical observation and accumulation of facts by trial and error".

\section{ORIGINS AND DEVELOPMENT OF TEK}

The intellectual root of traditional ecological knowledge system is in ethno-sciences (mainly ethno-botany) and human ecology. The field started with the documentation of lists of species used by different in- 
digenous groups and elaborated a science of folk taxonomies of plants and animals and later of other physical component such as soil and land. The science of folk taxonomies is frequently associated with the name of Harold Conklin, who in the decade of 1950 documented the extensive plants knowledge and classification systems of indigenous group such as the Hanunoo of the Philippines. The early literature on traditional ecological knowledge systems is not based on the spiritual and religious values of species and worldview of indigenous communities. After 1980s, the exertion in traditional ecological knowledge system focuses much on other kinds of ethno-sciences, including indigenous agriculture, indigenous land management, ethno-botany, ethno-zoology, ethno-veterinary, ethnopedology and ethno-medicine.

The shift of emphasis from the documentation of species used by indigenous groups and their taxonomy, to a consideration of functional relationship and mechanisms of harvesting and management practices, give rise to the field of traditional ecological knowledge system. The field borrows from the cultural ecological tradition of the anthropologist Julian Steward who emphasized the study of adaptive processes and argued that social organization itself may be considered as an ecological adaptation of an indigenous/traditional people to their local environment. The early study in this field includes the studies of forest and biodiversity conservation in tropical ecosystems and traditional resource management systems in coastal fisheries, agro-pastuarilsim in semi-arid areas and the livelihood strategy in the Arctic.

\section{NATURE OF TRADITIONAL AND SCIENTIFIC ECOLOGICAL KNOWLEDGE}

Despite its importance and recognition in the international arena after the 1980s, the relationship between scientific ecological knowledge and traditional ecological knowledge system has remained controversial. There are both similarities and differences between traditional ecological knowledge system and scientific ecological knowledge system. Both kinds of knowledge systems are ultimately based on observation of the environment and both result from the same intellectual process of creating order out of disorder. But they are different in a number of substantive ways. 
Science combines a particular set of values with systems of knowledge based on empirical and temporal observation, rationality, and logic, as opposed to felt truths or lived experience. In comparison to this traditional ecological knowledge system is viewed in a larger social context where it is more spatially oriented, inclusive and holistic in practice. These features craft traditional ecological knowledge systems in such a way that it cannot be separated from cultural practices, spirituality and way of indigenous people's lives. Western scientists gather quantitative data to build mathematical models of population dynamics. The models are used to calculate sustainable yields of resources. The yields are then recommended for implementations to decision makers as resources harvesting strategies or regulations. The traditional harvesters are more concerned with instant circumstances. In contrast, the western scientific knowledge is concerned with the yield estimation trends i.e. variation in quantity of resources.

\section{AREA AND METHOD OF DATA COLLECTION}

Lower Manang is lower part of Manang district and covers five VDCs i.e. Pisang, Chame, Tachi-Bagarchap, Dharapani and Thoche. This region also falls inside Annapurna Conservation Area (ACA). Traditionally this district is divided into three administrative blocks i.e. Nyeshang, Nar-Phoo and Gyasumdo. The inhabitants of Nyeshang are known by the name of Nyeshangba or more popularly by the name of 'Manange' and of Nar-Phoo by 'Narba'. The inhabitants of Gyasumdo are mixed group of Gurung (majority), Lama (immigrants from Tibet, but settled in Manang for two to three generations), Bista (a caste group that reflects Tibetan life-style culturally, religiously and ethically, but claims themselves as an affiliation to 'Thakuri' social group of midhills Nepal) and insignificant number of disadvantaged caste groups.

The total population of lower Manang according to National Census Report, 2001 is 4,042, and total household number is 936 with 5.4 average household sizes. Though the representative total 936 households head appear to be actual respondent for this study but, keeping in mind the sensitivity of the research problems and general attribute of traditional ecological knowledge system research, only 200 households were considered as true universe for this study. This is done to avoid 
non-native respondents who are living there for one or two generations as household spectator. Similarly the fresh (new) immigrants are also excluded from respondent list. As traditional ecological knowledge system is spatial specific and is based on local dialect, it is most essential to avoid such short-comings for doing effective research.

After the formation of sampling frame, 25\% of households (sampling units), which equals to fifty households were selected as respondents (sample) for this study using the systematic random sampling method. For finding out the first household number to be surveyed, lottery method was used. From this, other houses among the universe have been found out at each fourth interval to include in the sample list. Data gathered during field work are scrunized, classified and tabulated according to demand of issues discussed in different chapters. Quantitative data gathered from interview schedule were codified, in order to analyze it by using computer software program, Statistical Package for Social Sciences (SPSS) for windows. The attitude of respondents were measured in a strongly agree to strongly disagree (1-5) likert scaling method.

\section{FINDINGS AND DISCUSSION}

\section{TABOO AND CULTURAL PRACTICES AS A MECHANISM OF BIODIVERSITY CONSERVATION}

Taboos, generally, refer to unwritten and orally transmitted community rules that govern human behavior. These socio-cultural constraints plays major role in management of forest resources and ecosystems. Taboo system ranges from providing total protection of entire plant communities to protection of desired plant species, throughout or during critical stage of its life history. Both the Hindu and Buddhist of lower Manang follow ancestral worshiping and animism in the form of deity worship. Animism means the belief that a supernatural force animates and organizes the universe or the belief that things in nature, e.g. trees, mountains and the sky, etc. (all living and non-living things), have souls or consciousness. This belief system and affection towards nature, as a zoolatry (worshiping of animals) and totem (considering plants and animals sacred) have contributed much for protection of for- 
est/natural resources in lower Manang.

Cultural biodiversity denotes the links between biodiversity and human diversity. Cultural biodiversity is also known as 'deep ecology'. One of the most illustrative influences of Buddhist philosophy in nature and wildlife protection in case of lower Manang is the doctrine of rebirth. This doctrine holds a notion that human beings can be reborn as animal or an animal can be reborn as human being. This philosophy promotes the belief system that respecting wild animals in a way is a respecting to own ancestors. Buddhist monks from lower Manang consider the musk deer and blue sheep (Himalayan ungulates) as a zoolatry reincarnation of Lord Buddha. In the same way, snow leopard (Panthera uncia uncia), known as 'Pangche' is considered as one of the most sacred mammal species of Himalayas. The lower Manang communities give high religious values for number of Himalayan pheasants (large birds) and scavenger i.e. eagles and vultures. They have a common belief system that the Himalayan ungulates are created by the god to fed the 'Pangche' i.e. snow leopard. Protection of such top level predator wildlife species through religious values reduces the dependency of such predator species on domestic livestock. Understanding the construction mechanism of 'deep cultural ecology' and its implication, thus, plays a significant role for participatory wildlife management and biodiversity conservation in the higher Himalayas.

\section{EXCHANGE OF TRADITIONAL ECOLOGICAL KNOWLEDGE SYSTEM}

The exchange of knowledge system is important for continuous existence of traditional ecological knowledge. In general diffusion of traditional ecological knowledge system is important both for knowledge handover process and for its extension. Transmission of knowledge systems helps on imparting specific knowledge on species identification, skill to use particular tools and reminding customary laws. Based on mode of transmission the exchange of traditional ecological knowledge system can be categorized into two forms, i.e. formal and information mode. Similarly on the basis of level of transmission, it can be classified into vertical mode and horizontal mode of transmission. 


\section{FORMAL TRANSMISSION}

In lower Manang, formal mode of transformation of traditional ecological knowledge system is very weak. This is basically performed among social groups, connecting older generation (teachers) to younger generation (students).

\section{INFORMAL TRANSMISSION}

A teacher (diffuser) in this type of transmission is typically mother and/ or father of a learner. Informal mode of transmission is generally occupied by cultural performance which includes ceremonies, rituals and other cultural practices.

\section{VERTICAL MODE OF TRANSMISSION}

This is a mode of transmission that takes between members of two succeeding generations. It is done through putting knowledge into practice. The most common actors based in this form of transmission are parents (donors) to offspring (users) or from teachers to students. This type of transmission is practiced only between the family members of knowledge holder and is nearly eroded in case of lower Manang.

\section{HORIZONTAL MODE OF TRANSMISSION}

This denotes to transmission of knowledge systems within the chores of youth or within siblings. In case of lower Manang such type of transmission is practiced generally during the time of daily activities such as gathering in forest for various activities like herding, collecting fuel wood or harvesting wild food.

\section{KEY FINDINGS}

Different groups conceptualize traditional ecological knowledge systems differently. However, there are some areas of overlap, for example the entire respondents explain that traditional ecological knowledge is constructed in the process of local people's adaptation with nature. The lower Manang people's beliefs are centered on the concept of sacred species, sacred groves, and sacred landscape. 
Implication traditional...... Laudari

In lower Manang forest management is maintained by collective choice decisions of local people who operate under a common property arrangement. Cultural groups have implemented a series of rules (customary law) or social norms, for sustainable management of forest resources.

Traditional ecological knowledge is likely to be specialized by gender, age and personal experiences. In lower Manang females are comparatively excellent on ethno-botanical knowledge systems than their male partners. This is because of spending more time by females for harvesting various forest resources.

The major factors that contribute to erosion of traditional ecological knowledge systems are modernization and downbeat attitudes towards local institutions. Besides this a wide range of individual, cultural, biophysical and societal factors have been attributed to erosion of traditional ecological knowledge.

In lower Manang traditional ecological knowledge system associated with wild edible and medicinal plants seems to live and is effectively handing over down. This points out that the only one way of protecting and conserving such knowledge system is its continuous use and 'learning by doing or repetition'.

Forest of lower Manang can be divided into sacred forest and used forest. The sacred forest is further divided into spirits forest and religious forest. Spirit forest is again divided into ghost forest and worship forest. It is thus important to preserve and reactivate cultural resources, since cultural resources and natural resources are linked to each other which provides backup for endurance of 'TEK' systems.

Indigenous institution in lower Manang falls into five categories, which are social, religious, political, judicial and economic. This institution directly or indirectly plays role for sustainable management of forest/ natural resources.

\section{EPILOGUE}

Indigenous people and their communities have a vital role in environmental management. This is because of the application of their huge 
ethno-ecological knowledge systems through traditional forest management practices. It is not true that traditional ecological knowledge systems include all aspect of indigenous knowledge system. Traditional ecological knowledge systems are concerned only with the ecological information including spirituality, values, normative rules and cultural practices regarding common property resource management. Local or indigenous people have a deep level of traditional ecological knowledge system, which is developed on adaptation to their bio-physical environment. Taboo, one of the most disputed and complex sociocultural phenomena is a central configuration of traditional ecological knowledge systems.

Implication in itself is a broad term, which indicates the hidden role played by an object or subject or a phenomenon. Traditional ecological knowledge is an abstract knowledge, often known as living knowledge. Thus, it is very important to involve the implicative process of such knowledge systems into forest resources management practices. Studies have shown that tremendous ethno-ecological information are stored in the minds and culture of indigenous peoples, which has played a significant role for management of forest resources. Moreover, measuring the magnitude and volume of traditional ecological knowledge systems is a challenging task.

The socio-economic and other rival changes in lower Manang have restricted the chances of interactions between children and their elders at local level. It is very urgent to address this gap in order to reconnect children with elders and local level institutions. It has been proved that where there is high level of socio-economic diversification and personal mobility, there is high risk for erosion of 'TEK' systems. More importantly, compared to laws, rules or legislations, some taboos are more easily accepted by native people of rural areas. A view of nature involving a web of relationship is significant from conservation point of view. Briefly we can conclude that demographic, cultural, technological, economic and governance factors are directly or indirectly responsible for erosion of traditional ecological knowledge systems in lower Manang. It is realized at international level that a nation should recognize and therefore supports local people's identity, culture and interests. 
Implication traditional...... Laudari

\section{REFERENCES}

Berkes, F. (1999). Sacred Ecology: Traditional Ecological Knowledge and Resource Management System. London: Taylor and Francis.

Berkes, F. and Colding, J. (2008). "Rediscovery of Traditional Ecological Knowledge as Adaptive Management". USA: Ecological Society of United State of America.

Colding, J., and Folk, C. (2001). Social Taboos: "Invisible" Systems of Local Resource Management and Biological Conservation. Cambridge: Cambridge University Press, United Kingdom.

Frake, C.O. (1962). "Cultural Ecology and Ethnography." In American Anthropologist 64. pp: 53-59.

Warren, D.M. (1992). "Indigenous Knowledge Biodiversity Conservation and Development". A Keynote Address at International Conference on Conservation of Biodiversity in Africa, Nairobi Ken 